\title{
Initial Assessment of the Consolidation of Chalcogels into a Viable Waste Form
}

Fuel Cycle Research \& Development

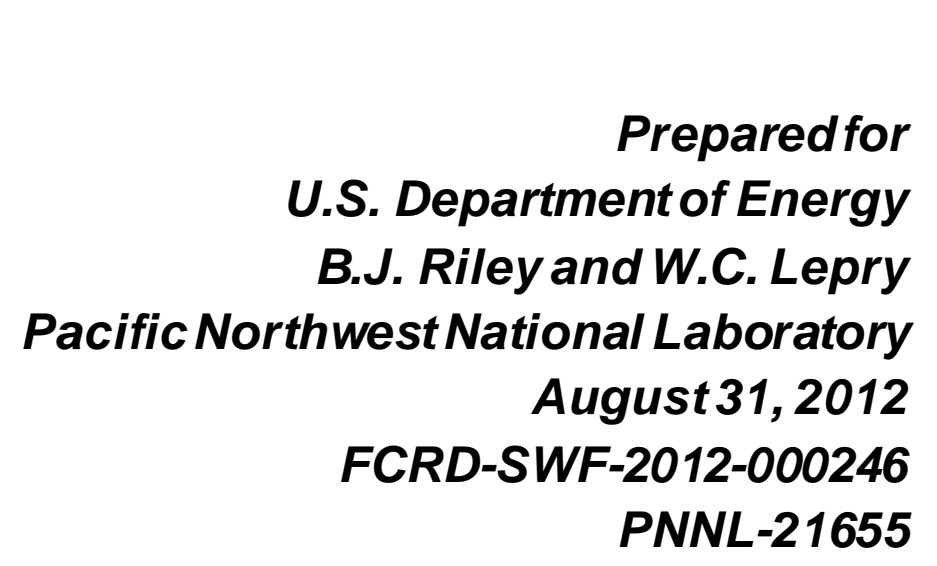




\section{DIS CLAIMER}

This information was prepared as an account of work sponsored by an agency of the U.S. Government. Neither the U.S. Government nor any agency thereof, nor any of their employees, makes any warranty, expressed or implied, or assumes any legal liability or responsibility for the accuracy, completeness, or usefulness, of any information, apparatus, product, or process disclosed, or represents that its use would not infringe privately owned rights. References herein to any specific commercial product, process, or service by trade name, trade mark, manufacturer, or otherwise, does not necessarily constitute or imply its endorsement, recommendation, or favoring by the U.S. Government or any agency thereof. The views and opinions of authors expressed herein do not necessarily state or reflect those of the U.S. Government or any agency thereof. 


\section{SUMMARY}

This report provides some preliminary data for the consolidation of chalcogen-based aerogels. The chalcogels tested to date at PNNL show great promise as iodine sorbents and preliminary consolidation research shows that they can be melted into a phase-pure glass at moderate temperatures. The preliminary consolidation experiments show that these materials might attack fused quartz so an alternative crucible material will likely need to be used to prevent this. The next steps will be to

- Consider melting other chalcogel chemistries, e.g., Sn-Sb-S, Ge-Sn-S chalcogels

- Consider melting chalcogels with adsorbed iodine to monitor iodine loss during melting

- Optimize the consolidation temperatures to minimize the iodine loss and volatilization 


\section{CONTENTS}

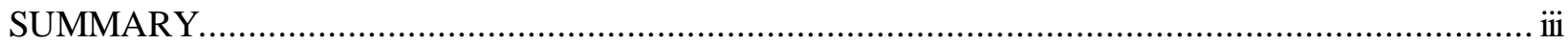

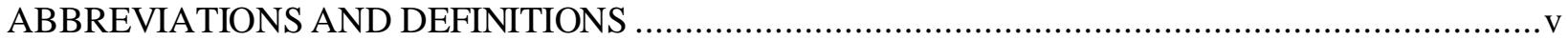

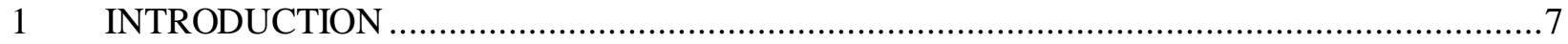

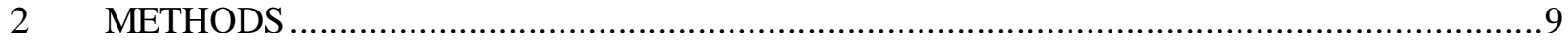

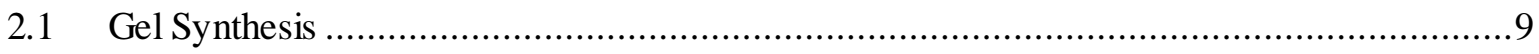

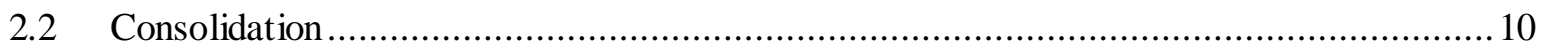

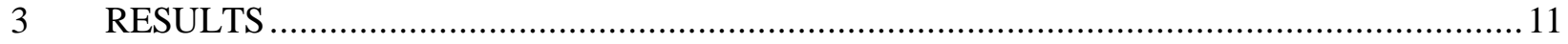

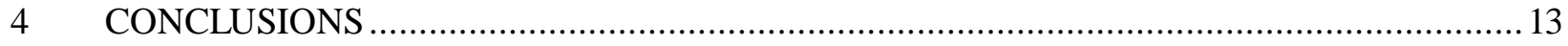

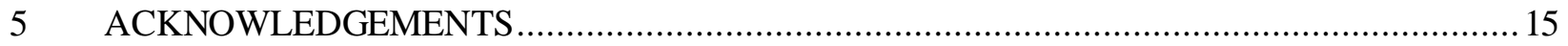

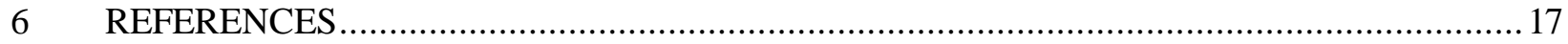

\section{FIGURES}

Figure 1. Glass formation tendency in Sn-Ge-S chalcogenide glasses (Ruffolo and Boolchand, 1985).

Figure 2. Progression of making $\mathrm{Sn}_{2} \mathrm{~S}_{3}$ chalcogels.

Figure 3. (left) As-measured and silica equivalent specific surface area as a function of degas temperature and (right) SEM micrograph of Sn-S chalcogel.

Figure 4. Progression of chalcogel consolidation in a fused quartz ampoule (as viewed through outer tube)

Figure 5. Optical and SEM micrographs of the heat-treated and polished Cg-17C-2 chalcogel.

Figure 6. XRD spectrum of portion of consolidated glass that was not mounted in resin for SEM observations. Minor quartz peaks were observed (Wyckoff, 1926).

\section{TABLES}

Table 1. Summary of non-Pt chalcogel chemistries (families). *AN: aggregation of nanocrystals;

CL: chemical linkage of clusters. 


\section{ABBREVIATIONS AND DEFINITIONS}

$\begin{array}{ll}\text { AN } & \text { aggregation of nanocrystals/nanoparticles (chalcogel fabrication method) } \\ \text { CL } & \text { chemical linkage of clusters (chalcogel fabrication method) } \\ \text { DIW } & \text { deionized water } \\ \text { EDS } & \text { energy dispersive spectroscopy } \\ M & \text { interlinking metal (used in CL method for chalcogel fabrication) } \\ \text { mmol } & \text { millimoles } \\ \text { N/A } & \text { not applicable } \\ \text { OAc } & \text { acetate (CH }{ }_{3} \text { COO') } \\ \text { PNNL } & \text { Pacific Northwest National Laboratory } \\ \text { psi } & \text { pounds per square inch } \\ \text { SEM } & \text { scanning electron microscopy } \\ \text { SSA } & \text { specific surface area } \\ \text { XRD } & \text { X-ray diffraction }\end{array}$





\section{INTRODUCTION}

A new family of non-oxide, chalcogen-based aerogels, called chalcogels, has been reported in the literature (Mohanan et al., 2005; Kalebaila et al., 2006; Bag et al., 2007; Kanatzidis and Bag, 2008; Bag et al., 2009; Bag and Kanatzidis, 2010; Oh et al., 2011; Yuhas et al., 2011b; Yuhas et al., 2011a; ShafaeiFallah et al., 2011; Riley et al., 2011; Polychronopoulou et al., 2012). These are highly porous semisolids made from a variety of S-, Se-, and/or Te-based building blocks that have selective affinity for various heavy metals and gases (Bag et al., 2007; Bag et al., 2009; Bag and Kanatzidis, 2010). Different methods have been discovered to make these chalcogels including (1) the aggregation of nanoparticles and (2) the chemical linkage of chalcogenido clusters with an interlinking metal (or metals). A comprehensive summary is provided in Table 1 (Riley et al., 2012).

Table 1. Summary of non-Pt chalcogel chemistries (families). *AN: aggregation of nanocrystals; CL: chemical linkage of clusters.

\begin{tabular}{|c|c|c|c|c|}
\hline $\begin{array}{l}\text { Chemistry } \\
\text { (Family) }\end{array}$ & Method ${ }^{*}$ & $\begin{array}{l}\text { Chalcogenido } \\
\text { cluster(s) }\end{array}$ & $\begin{array}{l}\text { Interlinking } \\
\text { metal(s), } M\end{array}$ & Reference(s) \\
\hline (Cd,Zn,Pb)-(S,Se) & AN & N/A & N/A & (Mohanan et al., 2005) \\
\hline Ge-S & AN & N/A & N/A & (Kalebaila et al., 2006) \\
\hline$(\mathrm{Mo}, \mathrm{W})-M-\mathrm{S}$ & CL & $(\mathrm{Mo}, \mathrm{W}) \mathrm{S}_{4}{ }^{2-}$ & $\mathrm{Co}^{2+}, \mathrm{Ni}^{2+}$ & $\begin{array}{l}\text { (Bag et al., 2009; Shafaei- } \\
\text { Fallah et al., 2011) }\end{array}$ \\
\hline (Sn,Sb)-M-(S,Se) & CL & $\begin{array}{l}\mathrm{Sn}_{2}(\mathrm{~S}, \mathrm{Se})_{6}{ }^{4-} \\
\mathrm{Sn}(\mathrm{S}, \mathrm{Se})_{4}{ }^{4-}, \mathrm{SbSe}_{4}{ }^{3-}\end{array}$ & $\mathrm{Sn}^{2+}, \mathrm{Sb}^{3+}$ & $\begin{array}{l}\text { (Bag and Kanatzidis, } \\
\text { 2010) }\end{array}$ \\
\hline Zn-Sn-S & CL & $\begin{array}{l}\mathrm{SnS}_{4}^{4-}, \mathrm{Sn}_{2} \mathrm{~S}_{6}^{4-} \\
\mathrm{Sn}_{4} \mathrm{~S}_{10}\end{array}$ & $\mathrm{Zn}^{2+}$ & (Oh et al., 2011) \\
\hline Fe-Sn-S & CL & $\mathrm{Fe}_{4} \mathrm{~S}_{4}{ }^{m-}, \mathrm{Sn}_{2} \mathrm{~S}_{6}{ }^{4-}$ & $\mathrm{Fe}_{4} \mathrm{~S}_{4}{ }^{m-}, \mathrm{Sn}_{2} \mathrm{~S}_{6}{ }^{4-}$ & (Yuhas et al., 2011b) \\
\hline Fe-M-Sn-S & CL & $\mathrm{Fe}_{4} \mathrm{~S}_{4}{ }^{m-}, \mathrm{Sn}_{2} \mathrm{~S}_{6}{ }^{4-}$ & $\begin{array}{l}\mathrm{Zn}^{2+}, \mathrm{Sn}^{2+}, \mathrm{Ni}^{2+}, \\
\mathrm{Co}^{2+}\end{array}$ & (Yuhas et al., 2011a) \\
\hline Mo-Co- $M$-S & CL & $\mathrm{MoS}_{4}{ }^{2-}$ & $\begin{array}{l}\mathrm{Co}^{2+}, \mathrm{Pb}^{2+}, \mathrm{Cd}^{2+}, \\
\mathrm{Pd}^{2+}, \mathrm{Cr}^{3+}, \mathrm{Bi}^{3+}\end{array}$ & $\begin{array}{l}\text { (Polychronopoulou et al., } \\
\text { 2012) }\end{array}$ \\
\hline
\end{tabular}

At the Pacific Northwest National Laboratory (PNNL), we have been studying these materials as sorbents for the radioiodine evolved during the proposed reprocessing of used nuclear fuel. While the concentrations of iodine are low, the required capture efficiencies are very high at $\geq 99.4 \%$ (40 CFR 190, 2012). The initial chalcogel materials tested at PNNL to date show promise as sorbents with $>99 \%$ capture efficiencies for low iodine concentrations in air (Riley et al., 2011; Riley et al., 2012).

Unlike the traditional iodine sorbents such as silver-exchanged zeolites, chalcogels do not require "functionalization" to bind the iodine. Silver is a precious metal and toxic per the Resource Conservation and Recovery Act (40 CFR 261, 2012). These make chalcogels an attractive material for removal of iodine from reprocessing off-gases. The mechanism by which chalcogels bind iodine is likely a combination of physisorption and chemisorption, whereas AgI is formed in any Ag-functionalized sorbent.

It has been shown that iodine is soluble in several different chalcogenide glasses and they can accommodate large fractions of iodine into their structure (Heo and Mackenzie, 1989; Wang et al., 2001; Krasteva et al., 1997b; Krasteva et al., 1997a; Seddon and Hemingway, 1991, 1993; Heo et al., 1987; Lin and Ho; Maneglier-Lacordaire et al., 1975; Turyanitsa et al., 1974). Like the other iodine capturing materials being considered (zeolite and silica aerogel), chalcogels have high surface area and porosity, they and require consolidation to collapse the pore structure with heating, for example to make them suitable for disposal. Chalcogels fall into a category of materials called chalcogenides and many chalcogenide compounds can be melted into glasses at moderate temperatures, e.g., typically $<700{ }^{\circ} \mathrm{C}$. The primary goal of this brief report is to demonstrate the melting of a chalcogel into a chalcogenide 
glass. These melted glasses potentially have high chemical durability. This is in contrast to oxide glasses where halides tend to remain as undissolved salts within the glass network or evolve from the glass surface during melting (Hrma, 2010). The preliminary results reported here fulfill the milestone "M3FT12PN03030912-Provide an initial assessment of the consolidation of chalcogels into viable waste forms" (FCRD-SWF-2012-000246).

From a glass formation standpoint, the most promising chalcogel chemistries are Sn-S and Sn-Se formulations that include Ge or Sb. Since Zn-Sn-S chalcogels tend to change from an amorphous aerogel to a crystalline material when heated (Oh et al., 2011), we suspect that the Sn-S chalcogels will crystallize as well. Therefore, this system probably requires a glass-forming additive in order to obtain a glassy product , e.g., Ge or Ge-S (Ruffolo and Boolchand, 1985) (Figure 1). Figure 1 shows the glass transition temperature $\left(T_{\mathrm{g}}\right)$, crystallization temperature $\left(T_{\mathrm{c}}\right)$, and value of $\left(T_{\mathrm{c}}-T_{\mathrm{g}}\right)$ for the $\mathrm{Sn}_{2} \mathrm{~S}_{3}-\mathrm{Ge}_{2} \mathrm{~S}_{3}$ binary system. The value of $\left(T_{\mathrm{c}}-T_{\mathrm{g}}\right)$ provides an estimate of ability to make a glass where a larger difference allows for slower quench rates to prevent glass crystallization and from Figure 1, it is evident that increased $\mathrm{Sn}_{2} \mathrm{~S}_{3}$ loadings decrease the glass formability.

It is possible to make a Sn-Ge-S chalcogel with the variety of Ge-S and Sn-S chalcogel precursors discovered to date that include $\mathrm{GeS}_{4}{ }^{4-}, \mathrm{Ge}_{4} \mathrm{~S}_{10}{ }^{4-}, \mathrm{SnS}_{4}{ }^{4-}, \mathrm{Sn}_{2} \mathrm{~S}_{6}{ }^{4-}$, and $\mathrm{Sn}_{4} \mathrm{~S}_{10}{ }^{4-}$ (Melullis and Dehnen, 2007; Bowes et al., 1996; Schiwy et al., 1973; Krebs et al., 1972; Tsamourtzi et al., 2008). Glass formation has been demonstrated in the Sb-Sn-S system with iodine (Turyanitsa et al., 1974). Thus, our focus is on these two systems-Sn-S with added Ge-S powder and Sb-Sn-S. Several techniques are evaluated for consolidating both the as-made and iodine-sorbed chalcogels. These include melting, hot pressing, and spark plasma sintering.
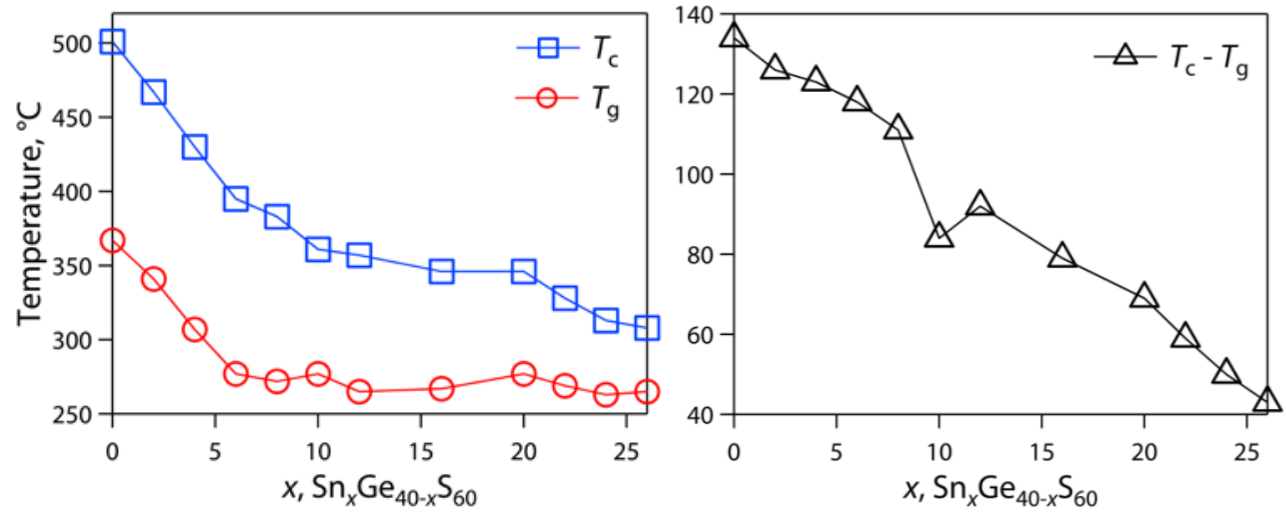

Figure 1. Glass formation tendency in Sn-Ge-S chalcogenide glasses (Ruffolo and Boolchand, 1985). 


\section{METHODS}

\subsection{Gel Synthesis and Characterization}

The Cg-17C-2 $\mathrm{Sn}_{2} \mathrm{~S}_{3}$ chalcogel was fabricated with solutions of $\mathrm{Na}_{4} \mathrm{Sn}_{2} \mathrm{~S}_{6}-14 \mathrm{H}_{2} \mathrm{O}$ and $\mathrm{SnCH}_{3} \mathrm{COO}$, or tin(II) acetate; hereinafter SnOAc. The $\mathrm{Na}_{4} \mathrm{Sn}_{2} \mathrm{~S}_{6}-14 \mathrm{H}_{2} \mathrm{O}$ was made with the procedure used by Oh et al. (2011) and the SnOAc was purchased from Sigma Aldrich. The $\mathrm{Na}_{4} \mathrm{Sn}_{2} \mathrm{~S}_{6}-14 \mathrm{H}_{2} \mathrm{O}$ compound was made by slowly adding solution (1) containing $20 \mathrm{mmol}(7.01 \mathrm{~g})$ of $\mathrm{SnCl}_{4}-5 \mathrm{H}_{2} \mathrm{O}$ in $5 \mathrm{~mL}$ of deionized water (DIW), to solution (2) containing $60 \mathrm{mmol}(14.41 \mathrm{~g})$ of $\mathrm{Na}_{2} \mathrm{~S}-9 \mathrm{H}_{2} \mathrm{O}$ in $100 \mathrm{~mL}$ of DIW, and mixing. The process of the chemical reaction that took place is presented in Equations 1a-1c where the species present at each step are defined (assuming 100\% yield). This mixture was added to $\sim 300 \mathrm{~mL}$ of acetone and, after stirring/shaking, a yellow emulsion was observed that eventually resulted in a white precipitate. The solution was kept in the refrigerator for a few days to increase the yield of the precipitate and then the precipitate was vacuum filtered with a Buchner funnel, washed with acetone, and dried in a vacuum desiccator.

Reactants:

$$
\begin{gathered}
20 \mathrm{SnCl}_{4}-5 \mathrm{H}_{2} \mathrm{O}+60 \mathrm{Na}_{2} \mathrm{~S}-9 \mathrm{H}_{2} \mathrm{O}+5828 \mathrm{H}_{2} \mathrm{O} \rightarrow \\
20 \mathrm{Sn}^{4+}+60 \mathrm{~S}^{-}+120 \mathrm{Na}^{+}+80 \mathrm{Cl}^{-}+6468 \mathrm{H}_{2} \mathrm{O} \rightarrow \\
10 \mathrm{Na}_{4} \mathrm{Sn}_{2} \mathrm{~S}_{6}-14 \mathrm{H}_{2} \mathrm{O}+80 \mathrm{Na}^{+}+80 \mathrm{Cl}^{-}+6328 \mathrm{H}_{2} \mathrm{O}
\end{gathered}
$$

Species in water:

Species in acetone: $\quad 10 \mathrm{Na}_{4} \mathrm{Sn}_{2} \mathrm{~S}_{6}-14 \mathrm{H}_{2} \mathrm{O}+80 \mathrm{Na}^{+}+80 \mathrm{Cl}^{-}+6328 \mathrm{H}_{2} \mathrm{O}$

To make the chalcogel, a scaled-up version of the process defined by Bag and Kanatzidis for ChalcogelSn-2 was followed (Bag and Kanatzidis, 2010). Here, 4 mmol (3.10 g) of $\mathrm{Na}_{4} \mathrm{Sn}_{2} \mathrm{~S}_{6}-14 \mathrm{H}_{2} \mathrm{O}$ was dissolved in $80 \mathrm{~mL}$ of formamide and $8 \mathrm{mmol}(1.89 \mathrm{~g})$ of SnOAc was dissolved separately in $80 \mathrm{~mL}$ of formamide $\left(\mathrm{CH}_{3} \mathrm{NO}\right)$. Then, the SnOAc solution was slowly added to the $\mathrm{Na}_{4} \mathrm{Sn}_{2} \mathrm{~S}_{6}-14 \mathrm{H}_{2} \mathrm{O}$ solution at which point, the solution turned from a clear (sometimes light blue) to a green, orange, and then dark maroon (see Figure 2). The chemical reaction that took place is presented in Equations 2a-2c where the species present at each step are defined (assuming 100\% yield).

$$
\begin{array}{lc}
\text { Reactants: } & 4 \mathrm{Na}_{4} \mathrm{Sn}_{2} \mathrm{~S}_{6}-14 \mathrm{H}_{2} \mathrm{O}+8 \mathrm{SnCH}_{3} \mathrm{COO}+4025 \mathrm{CH}_{3} \mathrm{NO} \rightarrow \\
\text { Before gelation: } & 4 \mathrm{Sn}_{2} \mathrm{~S}_{6}{ }^{4-}+8 \mathrm{Sn}^{2+}+16 \mathrm{Na}^{+} 8 \mathrm{CH}_{3} \mathrm{COO}^{-} \\
\text {After gelation: } & 8 \mathrm{Sn}_{2} \mathrm{~S}_{3}+16 \mathrm{Na}^{+}+8 \mathrm{CH}_{3} \mathrm{COO}^{-}+56 \mathrm{H}_{2} \mathrm{O}+4025 \mathrm{CH}_{3} \mathrm{NO}
\end{array}
$$
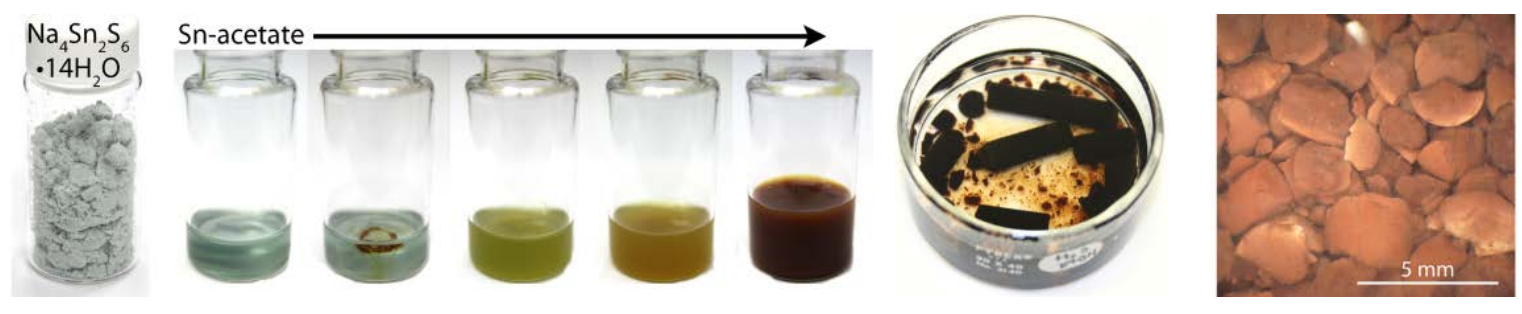

Figure 2. Progression of making $\mathrm{Sn}_{2} \mathrm{~S}_{3}$ chalcogels.

The solution was then poured into polypropylene vials with lids and zero headspace. These were covered with aluminum foil to exclude light, left to gel over the course of 4-5 weeks, after which the gels were removed from the vials, cut into $3-6 \mathrm{~mm}$ pieces, and placed in a 50/50 (v/v) ethanol/DIW mixture to age overnight. The aged gels were washed several times in fresh $50 \%$ ethanol to remove the water-soluble byproducts (Equation 2c). This was followed by several washes in $100 \%$ ethanol to remove the water.

The washed gels were submerged in fresh ethanol in an autoclave (4762Q, Parr Instruments) and placed in a temperature-controlled water bath at $10^{\circ} \mathrm{C}$. A syringe pump (Teledyne ISCO 500D) was used to slowly add liquid $\mathrm{CO}_{2}$ to a pressure of $6.9 \times 10^{6} \mathrm{~Pa}(1000 \mathrm{psi})$. This was repeated until approximately 1 to $2 \mathrm{~L}$ of liquid $\mathrm{CO}_{2}$ was flushed through autoclave to replace the ethanol. After the $\mathrm{CO}_{2}$ drying, the autoclave was left overnight with liquid $\mathrm{CO}_{2}$ at $1.0 \times 10^{7} \mathrm{~Pa}$. The next day, an additional $\mathrm{CO}_{2}$ wash was 
performed and the temperature of the water bath increased to $50^{\circ} \mathrm{C}$. Once the temperature equilibrated, the $\mathrm{CO}_{2}$ was vented from the autoclave resulting in an aerogel.

After degassing at $25,60,100$, and $125^{\circ} \mathrm{C}$ for $8 \mathrm{~h}$ at each temperature, the specific surface areas of these gels measured with nitrogen adsorption/desorption isotherms were 456, 432, 378, and $364 \mathrm{~m}^{2} / \mathrm{g}$, respectively (Figure 3). The specific surface areas of this chalcogel decreased with increasing degas temperature. This decrease could be due to the collapse of pore structure during evaporation of residual solvent in the gel network. A picture of a typical $\mathrm{Sn}_{2} \mathrm{~S}_{3}$ chalcogel is also presented in Figure 3.

In order to relate these chalcogels to the more common silica aerogel, a "silica equivalent specific surface area" is often used (Kanatzidis and Bag, 2008). Here, the chalcogel composition is normalized to two anions, e.g., $\mathrm{Sn}_{2.00} \mathrm{~S}_{3.00}$ becomes $\mathrm{Sn}_{1.33} \mathrm{~S}_{2.00}$ and the molecular mass of this compound (222.41 $\left.\mathrm{g} / \mathrm{mole}\right)$ is compared to that of $\mathrm{SiO}_{2}(60.08 \mathrm{~g} /$ mole) and the silica equivalent specific surface area (SSA) translates to $3.70 \times$ that of the values measured with the adsorption/desorption isotherms. These values are plotted on the right $y$-axis in Figure 3.
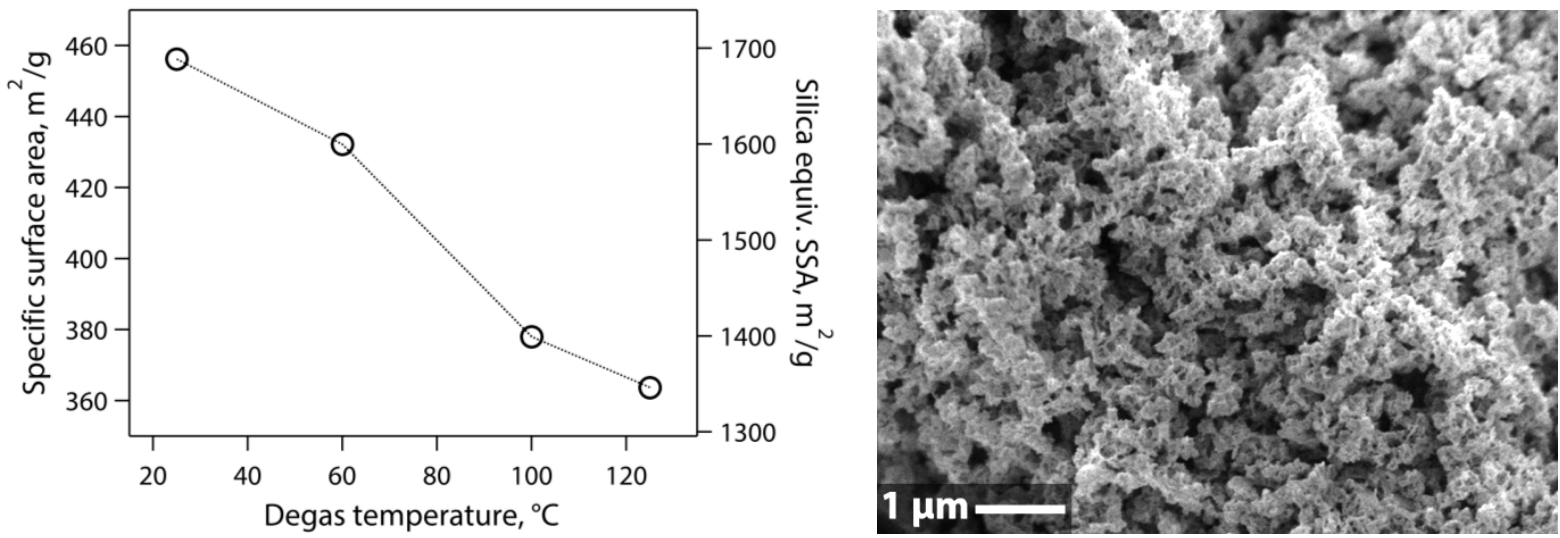

Figure 3. (left) As-measured and silica equivalent specific surface area as a function of degas temperature and (right) SEM micrograph of Sn-S chalcogel.

\subsection{Consolidation and Characterization}

Before consolidation, the Cg-17C-2 $\mathrm{Sn}_{2} \mathrm{~S}_{3}$ chalcogel was analyzed with scanning electron microscopy (SEM, JEOL 7001F, JEOL, Ltd) and energy dispersive spectroscopy (EDS, AMETEK Apollo XL) to verify the chemistry. The Sn:S ratio was $\sim 2: 3$, with inclusions of $\mathrm{Na}$, an impurity from the reactants (Equation 2c). The Cg-17C-2 chalcogel was weighed $(0.1786 \mathrm{~g})$ and added to a fused quartz tube $(10 \times 12$ $\mathrm{mm}$ along with $0.1464 \mathrm{~g} \mathrm{GeS}_{2}$, resulting in a $\mathrm{Sn}: \mathrm{Ge}=1$, on a molar basis, i.e., $\sim \chi=20$ in Figure 1 . This tube was added to a secondary tube $(22 \times 25 \mathrm{~mm})$ that was evacuated and sealed under vacuum. This assembly was loaded into a Deltech furnace (Deltech, Inc.) and heated to various temperatures, taken out briefly for observation, returned to the furnace, and heated to the next higher temperature. Observations were made at $400,550,750$, and $830^{\circ} \mathrm{C}$. At $830^{\circ} \mathrm{C}$, the sample was quenched in water. The inner ampoule was then mounted in resin, cross-sectioned, and polished for SEM/EDS observation.

The portion of the consolidated glass that was not mounted in resin was removed from the quartz tube, ground to a powder in an agate mortar and pestle, and analyzed with X-ray diffraction (XRD). The instrument was a Philips X'Pert with a radius of $190 \mathrm{~mm}$ and variable divergence and anti-scatter slits (10 $\mathrm{mm}$ irradiated area). The scan range was $5-90^{\circ} 2 \theta$ with 0.03 degree steps and a $2 \mathrm{~s}$ count at each step. The phases were identified with JADE® 6 software. 


\section{RESULTS}

Figure 4 shows a progression of the consolidation process. From these pictures it is readily apparent that the sample melted between 550 and $750{ }^{\circ} \mathrm{C}$. A likely processing temperature would be about $750{ }^{\circ} \mathrm{C}$ or slightly less. The yellow films observed on the walls of the quartz tube are very thin films of the chalcogenide glass that evaporated but condensed upon cooling (likely $<1$ mass\% of melt).

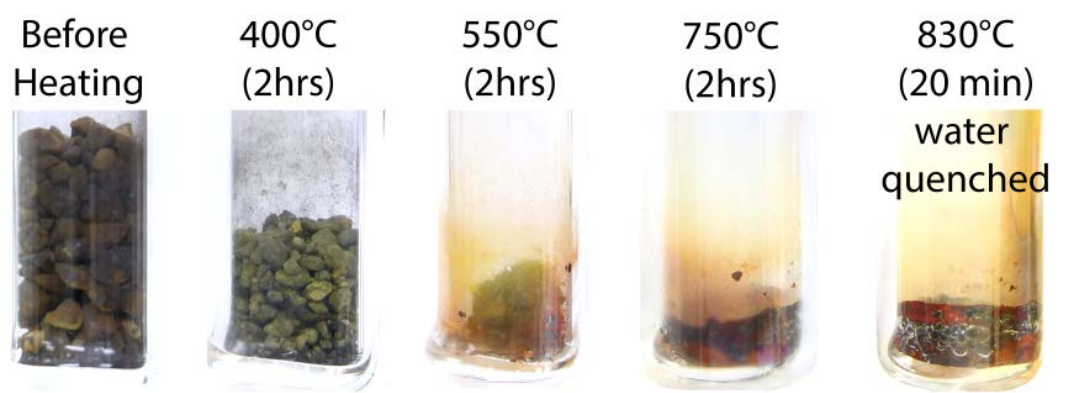

Figure 4. Progression of chalcogel consolidation in a fused quartz ampoule (as viewed through outer tube).

Figure 5 shows a complete and polished cross-section of the bottom portion of the sample quenched from $830{ }^{\circ} \mathrm{C}$. The bright red opaque glass is common to chalcogenides. Quenching the glass and the thermal expansion mismatch between the glass and the quartz likely caused the cracking - the molten glass attacked the fused quartz causing $\mathrm{SiO}_{2}$ particles to spall from the ampoule wall and into the melt (Figure 5b-d). Future experiments will be conducted with different crucible materials, e.g., alumina. Other than the $\mathrm{SiO}_{2}$ particles, the glass was completely homogeneous according to backscattered electron imaging and random area EDS analyses.
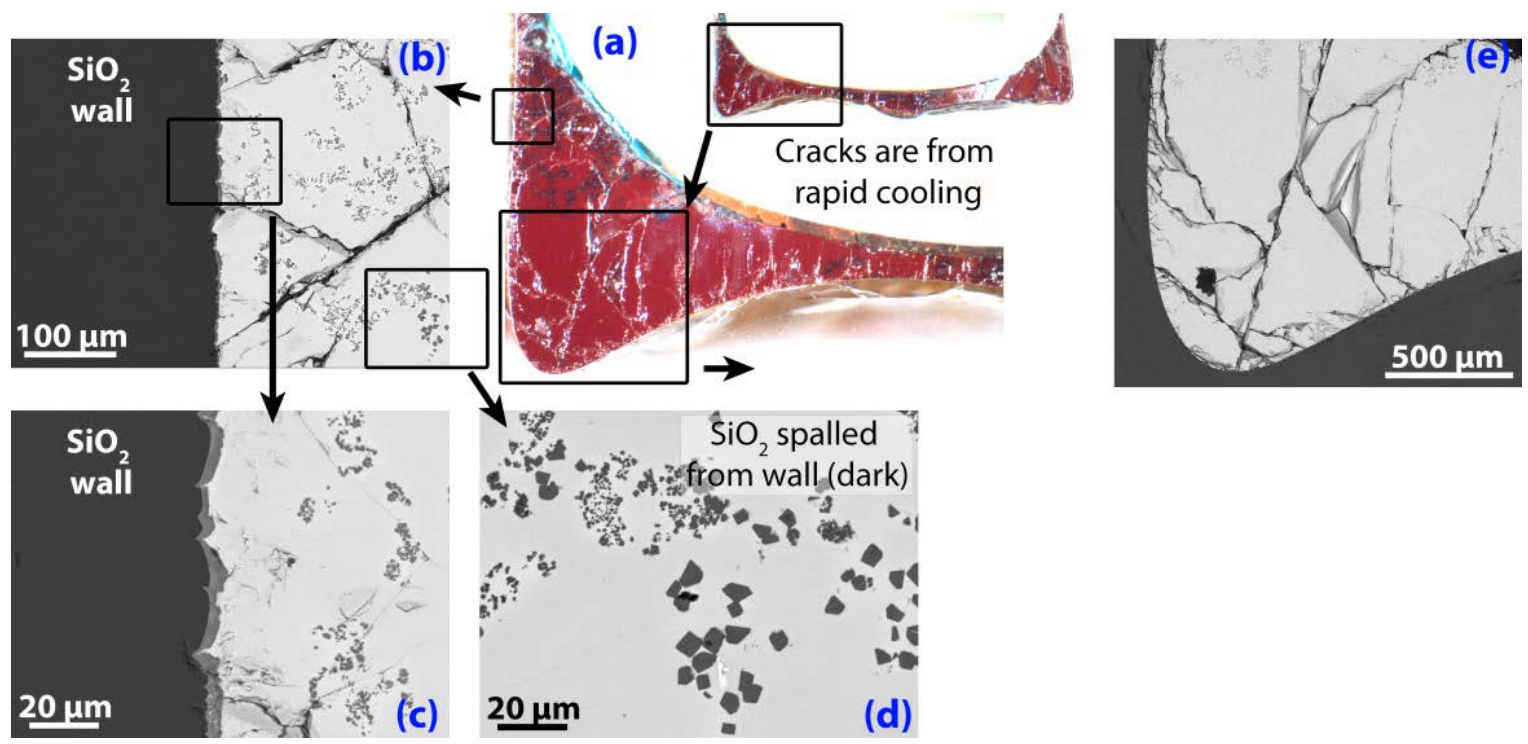

Figure 5. Optical and SEM micrographs of the heat-treated and polished Cg-17C-2 chalcogel.

Figure 6 provides the XRD spectrum of the powdered glass. The results show that XRD from the melted chalcogel has broad maxima characteristic of amorphous materials, e.g., chalcogenide glass. A few weak crystalline peaks were observed that were attributed to the quartz from the wall of the tube. 


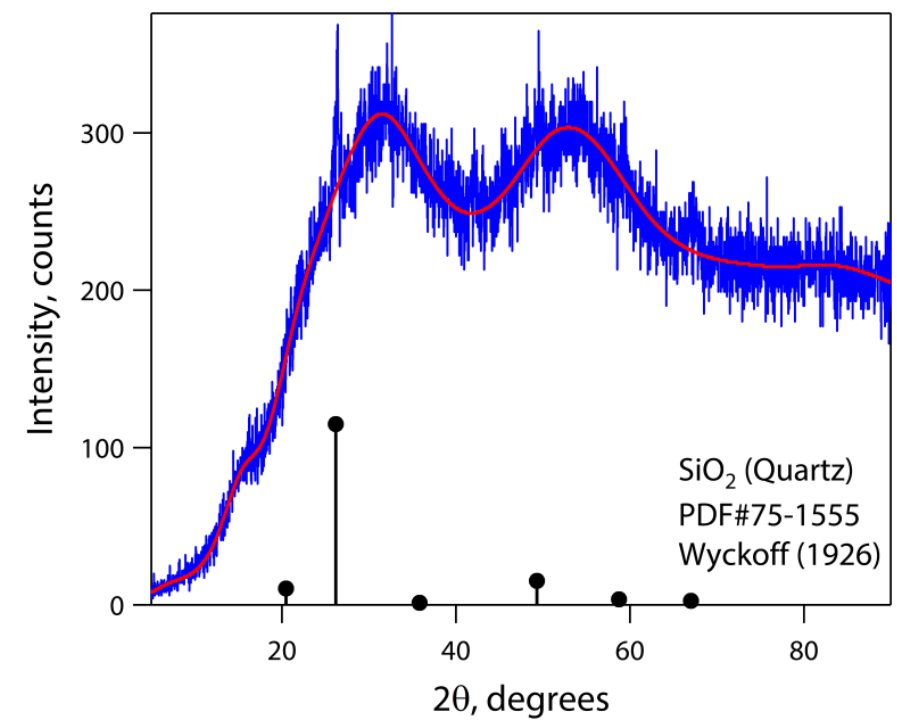

Figure 6. XRD spectrum of portion of consolidated glass that was not mounted in resin for SEM observations. Minor quartz peaks were observed (Wyckoff, 1926). 


\section{CONCLUSIONS}

The chalcogels tested to date at PNNL show great promise as iodine sorbents and preliminary consolidation research shows that they can be melted into a phase-pure glass at moderate temperatures. The preliminary consolidation experiments show that these materials might attack fused quartz so an alternative crucible material may be needed to prevent this. The next steps will be to

- make glasses from other chalcogel chemistries, e.g., Sn-Sb-S, Ge-Sn-S chalcogels

- Melt chalcogels containing iodine to monitor iodine loss

- Optimize the consolidation temperatures to minimize the iodine loss and volatilization 



\section{ACKNOWLEDGEMENTS}

The authors would like to thank the U.S. Department of Energy, Office of Nuclear Energy for their support of this work under Contract Number DE-AC05-76RL01830. We also thank John Vienna, John McCloy, and Loni Peurrung for helpful review of this document. 



\section{REFERENCES}

40 CFR 190. 2012. Environmental radiation protection requirements for normal operations of activities in the uranium fuel cycle. Environmental Protection Agency, Washington, D.C.

40 CFR 261. 2012. Identification and listing of hazardous waste. Environmental Protection Agency, Washington, D.C.

Bag, S, AF Gaudette, ME Bussell, and MG Kanatzidis. 2009. "Spongy chalcogels of non-platinum metals act as effective hydrodesulfurization catalysts." Nature Chemistry 1(3):217-24.

Bag, S and MG Kanatzidis. 2010. "Chalcogels: Porous Metal-Chalcogenide Networks from Main-Group Metal Ions. Effect of Surface Polarizability on Selectivity in Gas Separation." Journal of the American Chemical Society 132(42):14951-59.

Bag, S, PN Trikalitis, PJ Chupas, GS Armatas, and MG Kanatzidis. 2007. "Porous semiconducting gels and aerogels from chalcogenide clusters." Science 317(5837):490-93.

Bowes, CL, WU Huynh, SJ Kirkby, A Malek, GA Ozin, S Petrov, M Twardowski, and D Young. 1996. "Dimetal linked open frameworks: $\left[\left(\mathrm{CH}_{3}\right)_{4} \mathrm{~N}\right]_{2}\left(\mathrm{Ag}_{2}, \mathrm{Cu}_{2}\right) \mathrm{Ge}_{4} \mathrm{~S}_{10}$." Chemistry of Materials 8:2147-52.

Heo, J and JD Mackenzie. 1989. "Chalcohalide glasses: I. Synthesis and properties of Ge-S-Br and GeS-I glasses." Journal of Non-Crystalline Solids 111(1):29-35.

Heo, J, JS Sanghera, H Nasu, and JD Mackenzie. 1987. "The structure and properties of infrared transmitting chalcohalide glasses." Materials Science Forum 19-20(1):55-62.

Hrma, PR. 2010. Retention of Halogens in Waste Glass. Report No. PNNL-19361, Pacific Northwest National Laboratory, Richland, WA.

Kalebaila, KK, DG Georgiev, and SL Brock. 2006. "Synthesis and characterization of germanium sulfide aerogels." Journal of Non-Crystalline Solids 352(3):232-40.

Kanatzidis, MG and S Bag. 2008. "Semiconducting aerogels from chalcogenido clusters with broad applications." USA Application No. US 2008/0241050 A1.

Krasteva, V, D Hensley, and GH Sigel. 1997a. "The effect of compositional variations on the properties of rare-earth doped Ge-S-I chalcohalide glasses." Journal of Non-Crystalline Solids 222:235-42.

Krasteva, V, D Machewirth, and GH Sigel. 1997b. " $\mathrm{Pr}^{3+}$-doped Ge-S-I glasses as candidate materials for $1.3 \mu \mathrm{m}$ optical fiber amplifiers." Journal of Non-Crystalline Solids 213-214:304-10.

Krebs, VB, S Pohl, and W Schiwy. 1972. "Darstellung und Struktur von $\mathrm{Na}_{4} \mathrm{Ge}_{2} \mathrm{~S}_{6} \cdot 14 \mathrm{H}_{2} \mathrm{O}$ und $\mathrm{Na}_{4} \mathrm{Sn}_{2} \mathrm{~S}_{6} \cdot 14 \mathrm{H}_{2} \mathrm{O}$ " Zeitschrift fuer Anorganische und Allgemeine Chemie 393:241-52. 
Lin, FC and S-M Ho. 1963. "Chemical durability of arsenic-sulfur-iodine glasses." Journal of the American Ceramic Society 46(1):24-28.

Maneglier-Lacordaire, S, J Rivet, and J Flahaut. 1975. "Le systeme ternaire germanium-soufre-iode, construction du diagramme de phase et etude des verres." Annales de chimie et de physique 10(6):29199.

Melullis, M and S Dehnen. 2007. "Syntheses, crystal structures, UV-Vis spectra and first NMR spectra of new potassium salts of chalcogenogermanates." Z. Anorg. Allg. Chem. 633:2159-67.

Mohanan, JL, IU Arachchige, and SL Brock. 2005. "Porous semiconductor chalcogenide aerogels." Science 307:397-400.

Oh, Y, S Bag, CD Malliakas, and MG Kanatzidis. 2011. "Selective surfaces:high-surface-area zinc tin sulfide chalcogels." Chemistry of Materials 23(9):2447-56.

Polychronopoulou, K, C Malliakas, J He, and M Kanatzidis. 2012. "Selective Surfaces: Quaternary $\mathrm{Co}(\mathrm{Ni}) \mathrm{MoS}$-based Chalcogels with Divalent $\left(\mathrm{Pb}^{2+}, \mathrm{Cd}^{2+}, \mathrm{Pd}^{2+}\right)$ and Trivalent $\left(\mathrm{Cr}^{3+}, \mathrm{Bi}^{3+}\right)$ Metals for Gas Separation." Chemistry of Materials, DOI: 10.1021/cm301444p.

Riley, BJ, J Chun, JV Ryan, J Matyáš, XS Li, DW Matson, SK Sundaram, DM Strachan, and JD Vienna. 2011. "Chalcogen-based aerogels as a multifunctional platform for remediation of radioactive iodine." RSC Advances 1:1704-15.

Riley, BJ, WC Lepry, J Chun, and DM Strachan. 2012. Initial Assessment of Alternate Metals in Chalcogels. Report No. FCRD-SWF-2012-000136, Pacific Northwest National Laboratory, Richland, WA.

Ruffolo, D and P Boolchand. 1985. "Origin of Glass Formation." Physical Review Letters 55(2):242-45.

Schiwy, VW, S Pohl, and B Krebs. 1973. "Darstellung und Struktur von $\mathrm{Na}_{4} \mathrm{SnS}_{4} \cdot 14 \mathrm{H}_{2} \mathrm{O}$." Zeitschrift fuer Anorganische und Allgemeine Chemie 402:77-86.

Seddon, AB and MA Hemingway. 1991. "Thermal properties of chalcogenide-halide glasses in the system: Ge-S-I." Journal of Thermal Analysis and Calorimetry 37(9):2189-203.

Seddon, AB and MA Hemingway. 1993. "Thermal characterization of infrared-transmitting Ge-S-I glasses." Journal of Non-Crystalline Solids 161:323-26.

Shafaei-Fallah, M, R Alexander, AP Katsoulidis, J He, CD Malliakas, and MG Kanatzidis. 2011. "Extraordinary Selectivity of $\mathrm{CoMo}_{3} \mathrm{~S}_{13}$ Chalcogel for $\mathrm{C}_{2} \mathrm{H}_{6}$ and $\mathrm{CO}_{2}$ Adsorption." Advanced Materials 23(42):4857-60.

Tsamourtzi, K, J-H Song, T Bakas, AJ Freeman, PN Trikalitis, and MG Kanatzidis. 2008.

"Straightforward Route to the Adamantane Clusters $\left.\left[\mathrm{Sn}_{4} \mathrm{Q}_{10}\right]^{4-}(\mathrm{Q}) \mathrm{S}, \mathrm{Se}, \mathrm{Te}\right)$ and Use in the Assembly of 
Open-Framework Chalcogenides $\left(\mathrm{Me}_{4} \mathrm{~N}\right)_{2} \mathrm{M}\left[\mathrm{Sn}_{4} \mathrm{Se}_{10}\right]\left(\mathrm{M}=\mathrm{Mn}^{\mathrm{II}}, \mathrm{Fe}^{\mathrm{II}}, \mathrm{Co}^{\mathrm{II}}, \mathrm{Zn}^{\mathrm{II}}\right)$ Including the First Telluride Member $\left(\mathrm{Me}_{4} \mathrm{~N}\right)_{2} \mathrm{Mn}\left[\mathrm{Ge}_{4} \mathrm{Te}_{10}\right]$." Inorganic Chemistry 47(24):11920-29.

Turyanitsa, ID, IM Migolinets, BM Koperles, and IF Kopinets. 1974. "Investigation of glasses in the systems Sn-Sb-S-I and Pb-Sb-S-I." Neorganicheskie Materialy 10(8):1436-38.

Wang, Y, J Wells, DG Georgiev, P Boolchand, K Jackson, and M M. 2001. "Sharp rigid to floppy phase transition induced by dangling ends in a network glass." Physical Review Letters 87(18):185503-1.

Wyckoff, R. 1926. "Kriterien fuer hexagonale Raumgruppen und die Kristallstruktur von beta Quarz." Zeitschrift fuer Kristallographie, Kristallgeometrie, Kristallphysik, Kristallchemie 63:507-39.

Yuhas, BD, C Prasittichai, JT Hupp, and MG Kanatzidis. 2011a. "Enhanced Electrocatalytic Reduction of $\mathrm{CO}_{2}$ with Ternary Ni-Fe ${ }_{4} \mathrm{~S}_{4}$ and $\mathrm{Co}-\mathrm{Fe}_{4} \mathrm{~S}_{4}$-Based Biomimetic Chalcogels." Journal of the American Chemical Society 133(40):15854-57.

Yuhas, BD, AL Smeigh, APS Samuel, Y Shim, S Bag, AP Douvalis, MR Wasielewski, and MG Kanatzidis. 2011b. "Biomimetic Multifunctional Porous Chalcogels as Solar Fuel Catalysts." Journal of the American Chemical Society 133(19):7252-55. 